\title{
Pelatihan \& Implementasi Social Media Profiling Untuk Meningkatkan Kompetensi Pada SMA Negeri 3 Semarang
}

\author{
Indra Gamayanto ${ }^{1}$,Sendi Novianto ${ }^{2}$, Hanny Haryanto ${ }^{3}$ \\ ${ }^{1,2,3,4,5}$ Departemen Sistem Informasi \& Teknik Informatika, Fakultas Ilmu Komputer, \\ Universitas Dian Nuswantoro, Semarang \\ E-mail: ${ }^{1}$ indra.gamayanto@dsn.ac.id, ${ }^{2}$ sendi.novianto@dsn.dinus.ac.id, \\ hanny.haryanto@dsn.dinus.ac.id
}

\begin{abstract}
Abstrak
Social media adalah P2P, dimana kita banyak mengalami perubahan hidup, saat social media telah masuk ke dalam proses sehari-hari. social media menjadikan kita lebih cepat dan lebih efektif serta efesien dalam melakukan sesuatu, seperti: cara kita berkomunikasi, memperluas jaringan pertemanan untuk mengenal orang-orang baru dan koneksi, mengembangkan market melalui business online dan memberikan pengaruh kepada orang lain melalui kepemimpinan kita di social media. Artikel ini merupakan pengembangan dan pelatihan yang kita berikan di SMA Negeri 3 Semarang dengan mengacu pada hasil penelitian yang telah kami publikasikan sebelumnya. Siswa dan guru akan mampu memahami bagaimana cara memperluas produk/jasa yang ditawarkan oleh melalui business online, melalui lingkaran internal dan eksternal yang diperluas, berikutnya kita akan mampu memahami bagaimana cara menjadi seorang netizen yang bijaksana mulai dengan memiliki pengetahuan, data yang valid, contoh-contoh studi kasus dan implementasi serta solusi yang kita berikan sehingga akan dapat meningkatkan inovasi dalam memecahkan sebuah masalah. Lebih jauh lagi, kita akan memahami tipe-tipe kepemimpinan di social media, sehingga kita dapat mengetahui kita adalah tipe apa dalam hal memimpin dan memberikan pengaruh kepada orang lain melalui social media. Hasil dari pengabdian masyarakat, pelatihan dan penelitian ini adalah meningkatnya kompetensi siswa dan guru dalam menghadapi globalisasi dan pemahaman yang mendalam mengenai penggunaan social media secara lebih efektif, efesien, tepat sasaran dan mampu bersaing secara global.
\end{abstract}

Kata kunci: Social media, Profiling, Sumber Daya Manusia, Komunikasi, Wise netizen

\begin{abstract}
Social media is $P 2 P$, where we have experienced many life changes, when social media has entered into our daily processes. social media makes us faster and more effective and efficient in doing things, such as: the way we communicate, expand our network of friends to get to know new people and connections, develop markets through online business and influence others through our leadership in social media. This article is a development and training that we provide at SMA Negeri 3 Semarang by referring to the research results that we have previously published. Students and teachers will be able to understand how to expand the products / services offered by online business, through expanded internal and external circles, then we will be able to understand how to become a wise netizen starting with having knowledge, valid data, examples-examples of case studies and implementation as well as solutions that we provide so that it will increase innovation in solving a problem. Furthermore, we will understand the types of leadership in social media, so that we can find out what type we are in terms of leading and influencing others through social media. The results of this community service, training and research are the increased competence of students and teachers in facing globalization and a deep understanding of the use of social media more effectively, efficiently, right on target and able to compete globally.
\end{abstract}

Keywords: Social media, Profilling, Human Resource, Communication, Wise netizen 


\section{PENDAHULUAN}

Social media mengubah hampir seluruh pola kehidupan kita saat ini, dengan terdapatnya social media, perubahan yang terjadi menjadi signifikan, sebagai contoh: kita dapat memperoleh informasi dengan cepat, kita dapat berkomunikasi secara lebih efektif dan efesien, dan memperluas koneksi kita dengan orang-orang baru[1],[2],[3]. Social media adalah P2P (people to people), artinya kita berhubungan dengan berbagai macam orang dan hal ini dapat mengubah paradigma kita dalam pola-pola kebiasaan dan kebudayaan yang baru. Dampak yang ditimbulkan oleh social media sangat besar, dan hal ini tentunya menimbulkan dua dampak yaitu dampak efek domino dan efek wind, pada efek domino- apa yang kita katakan memberikan dampak luas kepada orang lain dan efek wind, merupakan sebuah dampak yang hanya bersifat sementara dan pada awalnya meluas kemudian menghilang dan informasi tersebut menghilang seiiring waktu[4],[5],[6]. Pada artikel ini focus kami adalah memberikan pemahaman yang mendalam mengenai social media profiling, dimana konsep ini adalah berbicara tentang bagaimana aspek-aspek atau parameter/indicator internal dan eksternal akan dapat berpengaruh kepada perilaku/sikap, kebiasaan dan cara kita berkomunikasi. Hal-hal tersebut harus dapat dipahami dengan tepat karena akan dapat memberikan pengaruh para perubahan diri kita sendiri dan juga orang lain[7],[8].

Artikel ini menggunakan metode yang sudah pernah dipublikasikan dan penerapannya adalah kami memberikan pelatihan mengenai pengembangan dan penerapan dari social media profiling dan bagaimana kita dapat meningkatkan kompentensi dan memahami manusia dari sisi psikologi komunikasi serta cara-cara dalam meningkatkan keuntungan dalam business online dengan menggunakan social media. SMA Negeri 3 semarang, merupakan salah satu SMA dan berusaha terus meningkatkan sumber daya manusianya, terutama guru dan siswa-siswanya serta mengadopsi inovasi dan hal-hal baru sehingga akan mampu menghadapi persaingan global yang terjadi pada saat ini. Hasil dari artikel ini adalah sebuah framework dan konsep-konsep yang inovatif, yang mampu meningkatkan tingkat pemahaman kita di bidang social media dari beberapa aspek, antara lain: psikologi komunikasi, kepemimpinan di social media dan social media-business online.

\section{METODE}

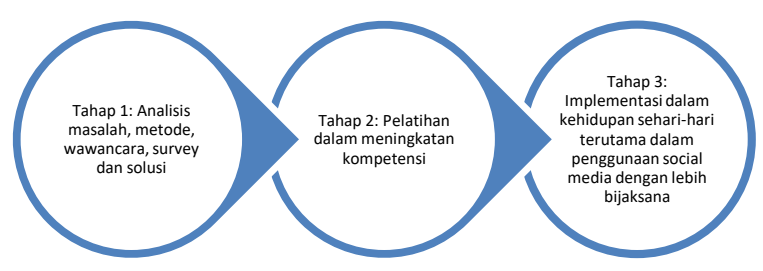

Gambar 1. Proses Penelitian dan Pelatihan di SMA Negeri 3 Semarang

Gambar 1, menjelaskan tahapan penelitian, pengabdian dan pelatihan di SMA Negeri 3 Semarang. Tahap pertama adalah kami melakukan wawancara untuk menemukan kebutuhan apa saja untuk meningkatkan komptensi di SMA Negeri 3 Semarang, dan mendiskisan model pelatihan yang diperlukan. Tahap kedua adalah melakukan pelatihan dan pembelajaran secara komprehensif di SMA Negeri 3 Semarang. Tahap ketiga merupakan tahap akhir, kami menjelaskan cara bagaimana hal-hal yang telah dijelaskan tersebut dapat diimplementasikan 
dalam kehidupan sehari-hari. metode yang kami gunakan dalam mengembangkan pelatihan ini adalah sebagai berikut:

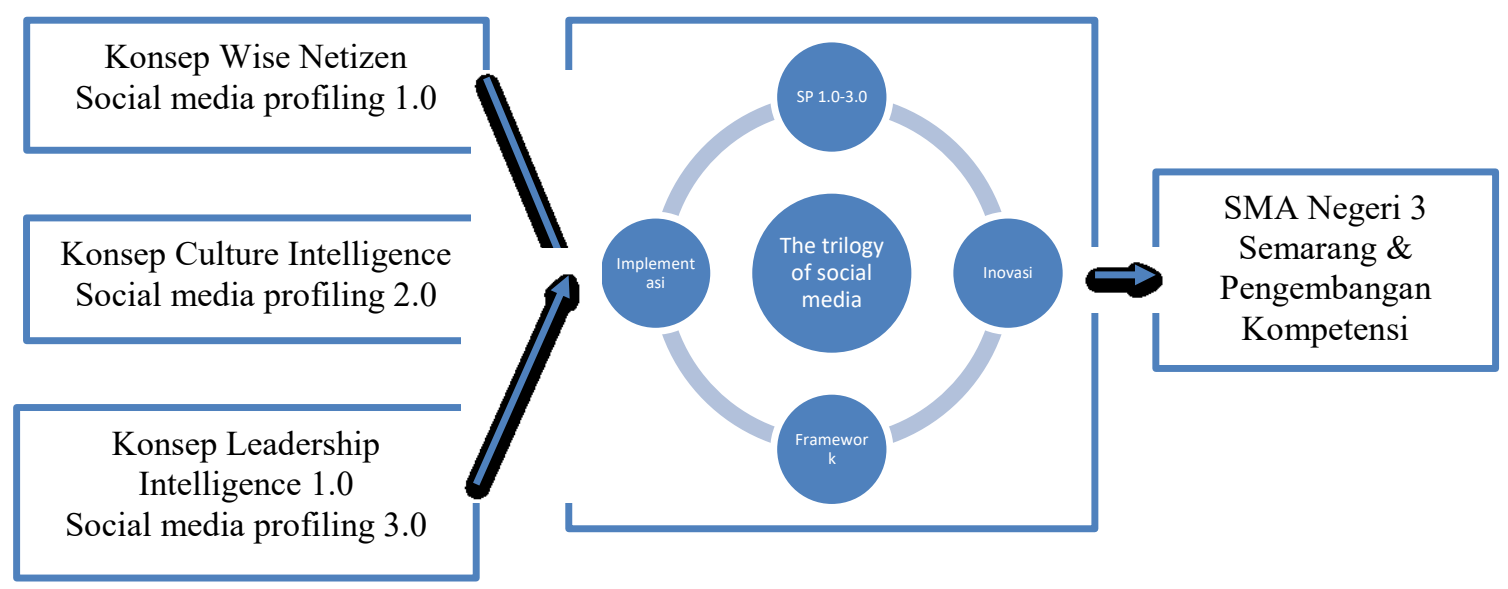

Gambar 2. Metode, Proses dan Implementasi

Gambar 2, menjelaskan metode dan tahapan dalam melakukan pelatihan dan pengabdian, prosesnya adalah sebagai berikut: (1) Mengajarkan tiga konsep utama dalam social media profiling, dimana di sini akan dapat dipahami mengenai dasar konsep dari wise netizen, budaya di social media dan kepemimpinan yang terdapat di social media; (2) Pemahaman lebih mendalam mengenai the trilogy of social media: mengenai bagaimana social media dapat digunakan sebagai jembatan dalam melakukan inovasi dari beberapa hal seperti- bidang business online, komunikasi efektif dan pengembangan kompetensi; serta menghasilkan sebuah framework dan bagaimana cara mengimplementasikan hal tersebut; (4) Pelatihan, pembelajaran dan implementasi, pada tahapan ini siswa SMA Negeri 3 Semarang dan guru akan mampu memahami secara utuh konsep social media profiling dan cara mengimplementasikannya dalam kehidupan sehari-hari.

\section{HASIL DAN PEMBAHASAN}

A. Kegiatan Pengabdian Masyarakat Di SMA Negeri 3 Semarang

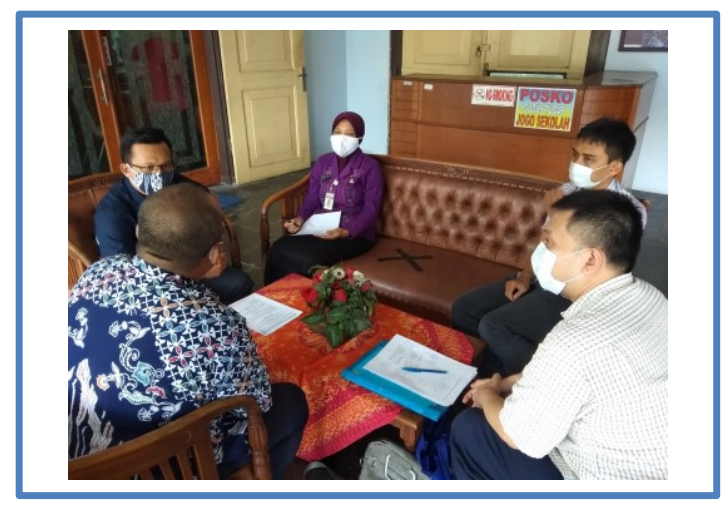

Gambar 3. Proses pertama: wawancara dan mengoleksi data

Pada gambar 3, dijelaskan kami melakukan wawancara dengan SMA Negeri 3 Semarang, Bpk. Sarojo, S.Pd, M.Pd dan Ibu Fitri. Pada hasil wawancara ini, kami menemukan bahwa pengembangan komptensi dalam bidang social media profiling sangat dibutuhkan karena hal ini akan dapat membantu para siswa untuk memahami dan dapat menggunakan social media 
dengan bijaksana. Lebih jauh lagi, diharapkan siswa juga akan dapat memahami cara-cara menjadi seorang wise netizen, sehingga akan sangat berguna bagi mereka dalam meningkatkan etika dalam ber social media dan dapat dikembangkan ke arah yang positif, sehingga dapat berguna bagi diri sendiri dan orang lain.

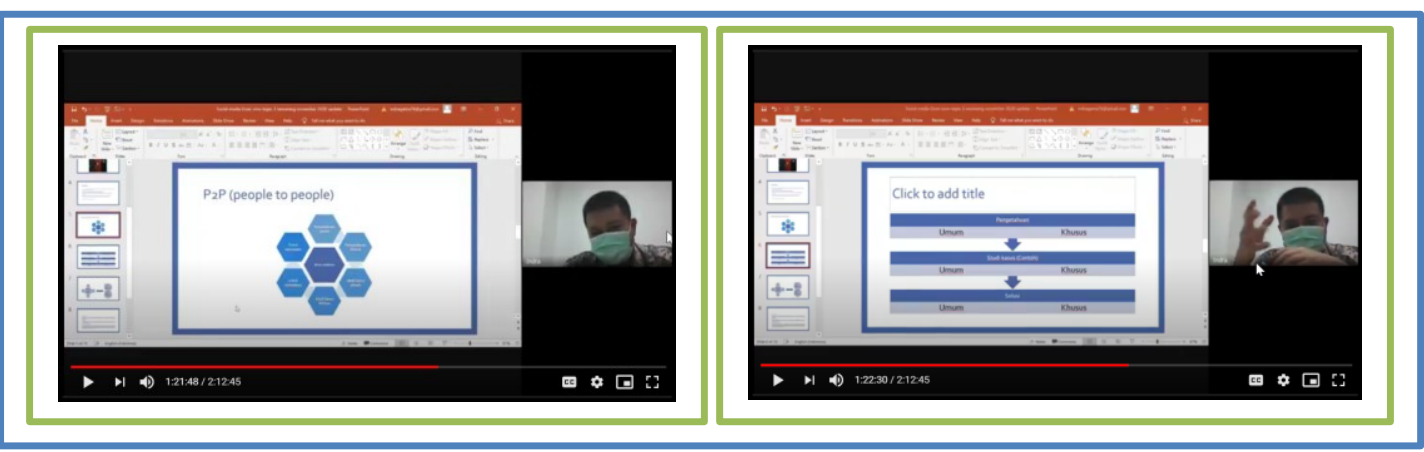

Gambar 4. Proses kedua: pelatihan social media profiling

Pada gambar 4, dijelaskan bahwa social media dapat mengubah banyak hal dalam kehidupan kita sehari-hari, seorang netizen, harus dapat memiliki beberapa hal penting, antara lain pengetahuan, studi kasus dan solusi. Ketiga hal tersebut, tidak dapat dipisahkan satu sama lain, ketiga-tiganya adalah kesatuan.

\section{B. Konten Pelatihan}

Pelatihan 1

Konsep ini adalah merupakan konsep bagaimana kita mengembangkan sebuah jaringan agar lebih luas dalam berjualan di business online. Konsep ini dapat digambarkan sebagai berikut:

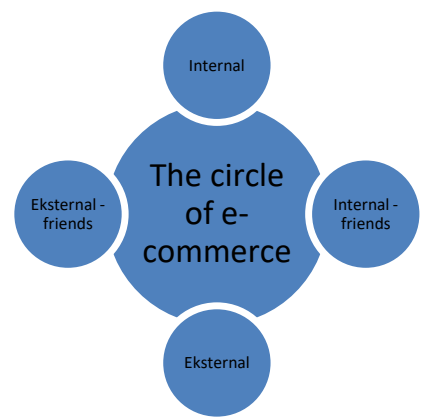

Gambar 5. The circle of e-commerce

Gambar 5, menjelaskan, pada saat kita ingin memperluas sebuah jaringan dalam menawarkan dan menjual sebuah produk/jasa yang kita miliki, kita bisa memulainya dari factor internal, di sini factor internal memiliki dua factor penting yaitu di dalam keluarga kita dan saudara dari keluarga kita sendiri, kita dapat menawarkan terlebih dahulu kepada keluarga kita sendiri dan saudara-saudara untuk merasakan manfaat dari produk/jasa yang kita miliki, kemudian tahap berikutnya adalah kita meminta rekomendasi dari keluarga kita, yaitu teman-teman dari keluarga kita yang kemudian kita menawarkan produk/jasa kita berdasarkan rekomendasi keluarga. Hal ini positif karena akan membuat orang lain mempercayai apa yang kita tawarkan, oleh karena kita sudah menerapkannya terlebih dahulu kepada keluarga kita sendiri[9],[10]

Pelatihan 2 
Pada bagian ini, konsep wise netizen dijelaskan, di sini kita akan belajar bagaimana menjadi seorang netizen yang bijaksana dalam menggunakan social media sehingga dapat memberikan dampak positif bagi orang lain. Hal ini dapat digambarkan sebagai berikut:

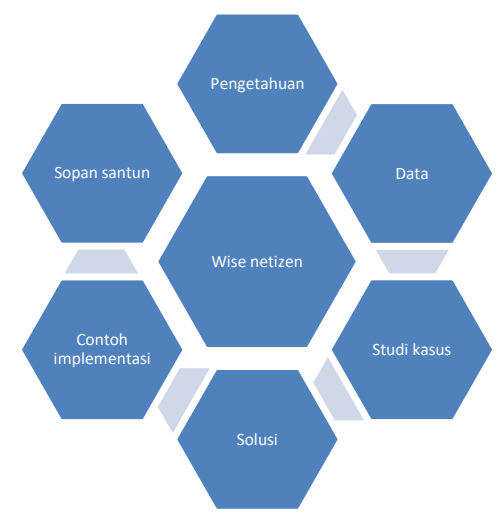

Gambar 6. How to become a wise netizen

Gambar 6, menjelaskan bahwa untuk menjadi seorang wise netizen, pertama-tama kita harus benar-benar memiliki pengetahuan yang tinggi dan memiliki data yang valid, kita dapat saja mengemukakan pendapat kita tetapi jika kita tidak memiliki dasar yang kuat untuk apa yang kita kemukakan, hal tersebut akan dapat berdampak negatif kepada orang lain. Dampak positif dari memiliki pengetahuan dan data, orang lain akan dapat yakin bahwa apa yang dikatakan oleh kita merupakan hal-hal yang berguna dalam meningkatkan pengetahuan dan mengubah sikap kita terhadap lingkungan di sekitar kita. Lebih jauh lagi, seorang wise netizen, juga harus dapat mengemukan contoh studi kasus dari data yang dimilikinya, dan memberikan contoh implementasi serta solusi untuk mengatasi sebuah masalah. kita dapat memberikan masukan dan pendapat alternatif untuk dapat membantu penyelesaian masalah secara lebih bijakana. Terakhir adalah kita harus dapat menggunakan bahasa yang sopan pada saat berkata-kata di social media, hal ini dapat meningkatkan perasaan empati kita terhadap orang lain dan belajar akan hal-hal baru guna meningkatkan kompetensi kita dari cara kita berpikir dan memecahkan sebuah masalah[11],[12],[13],[14].

\section{Pelatihan 3}

Bagian ini adalah merupakan tahap akhir dari pelatihan, dimana kita harus dapat memahami konsep budaya dan kepemimpinan di social media, agar kita dapat memberikan pengaruh positif kepada orang lain dengan cara yang elegan dan professional. Kepemimpinan di social media dapat dibagi menjadi lima tipe kepemimpinan, antara lain: compulsive, narcisstic, paranoid, condependent, pasif-agresif[15]. Kelima tipe ini dapat di test melalui table-tabel berikut ini:

Test Untuk mengetahui Apakah anda pemimpin kompulsif?[16]

1-Sangat tidak setuju; 2-Tidak setuju; 3-Ragu-ragu; 4-Setuju; 5-Sangat setuju

Tabel 1. Test Pemimpin Kompulsif

\begin{tabular}{|l|rll|}
\hline Saya sering khawatir bahwa atasan saya tidak menerima kualitas pekerjaan saya & 12345 \\
\hline $\begin{array}{l}\text { Saya sangat diatur dalam rutinitas pribadi harian saya seperti jadwal olahraga atau } \\
\text { disiplin rohani }\end{array}$ & 12345 \\
\hline $\begin{array}{l}\text { Ketika keadaan menuntut sehingga saya harus melanggar rutinitas harian saya, saya } \\
\text { merasa diri saya berada di luar aturan dan bahkan bersalah telah melewatkan satu hari }\end{array}$ & 12345 \\
\hline Saya sering kali meragukan status saya dalam berelasi dengan orang lain & 12345 \\
\hline $\begin{array}{l}\text { Sulit bagi saya mengambil satu hari libur di luar rencana dari tanggung jawab kerja } \\
\text { hanya untuk berkeliling atau meluangkan waktu bersama teman atau keluarga. Jika saya } \\
\text { melakukannya saya merasa seperti seorang pemalas }\end{array}$ & 12345 \\
\hline Ketika jauh dari pekerjaan, saya tetap mendapati diri saya memikirkan topic-topik yang & 12345 \\
\hline
\end{tabular}




\begin{tabular}{|l|cc|}
\hline $\begin{array}{l}\text { berhubungan dengan pekerjaan, seringkali duduk menulis ide-ide saya secara rinci, } \\
\text { bahkan menganggu aktivitas-aktivitas keluarga }\end{array}$ & & \\
\hline $\begin{array}{l}\text { Saya suka merencanakan details-details liburan saya agar saya tidak menyia-nyiakan } \\
\text { waktu atau melewatkan hal-hal yang penting }\end{array}$ & 12345 \\
\hline $\begin{array}{l}\text { Saya sering marah-marah setelah disalip ketika sedang mengemudi atau dibuat jengkel } \\
\text { oleh isu-isu yang sepele }\end{array}$ & 35 \\
\hline $\begin{array}{l}\text { Saya sangat teliti terhadap penampilan saya, sepatu tetap mengkilap, pakaian disetrika } \\
\text { dengan baik, rambut dipotong secara teliti dan dirapihkan dan kuku-kuku dipotong }\end{array}$ & 12345 \\
\hline $\begin{array}{l}\text { Saya sering menggerutu tentang jam kerja yang panjang dan beban pekerjaan yang } \\
\text { berat namun secara diam-diam saya bangga terhadap "etika kerja" saya }\end{array}$ & 1235 \\
\hline $\begin{array}{l}\text { Ketika orang lain membuat kekeliruan kecil atau kurang memperhatikan detail, saya } \\
\text { menjadi tersinggung dan menghakiminya }\end{array}$ & 12345 \\
\hline $\begin{array}{l}\text { Saya obsesif terhadap kekeliruan-kekeliruan yang paling kecil, khawatir kekeliruan- } \\
\text { kekeliruan itu akan merefleksikan saya dengan buruk }\end{array}$ & 12345 \\
\hline
\end{tabular}

Jumlahkan bilangan yang dilingkari dan tempatkan jumlahnya di sini:

Jika jumlah kurang dari 20, mungkin anda bukan kompulsif. Jika jumlah anda di antara 21 dan 40 ada kemungkinan anda memiliki beberapa kecenderungan kompulsif. Jika jumlah anda adalah 41 atau lebih, anda mungkin adalah seorang pemimpin yang kompulsif

Test Untuk mengetahui Apakah anda pemimpin narsistik?[17]

1-Sangat tidak setuju; 2-Tidak setuju; 3-Ragu-ragu; 4-Setuju; 5-Sangat setuju

Tabel 2. Test Pemimpin Narsisistik

\begin{tabular}{|l|llll|}
\hline $\begin{array}{l}\text { Citra pemimpin di dalam organisasi saya sering menanyakan apakah sasaran-sasaran } \\
\text { atau proyek-proyek yang saya ajukan itu baik dan realistik }\end{array}$ & 12345 \\
\hline $\begin{array}{l}\text { Saya terobsesi untuk mengetahui bagaimana pendapat orang lain tentang penampilan } \\
\text { saya }\end{array}$ & 12345 \\
\hline $\begin{array}{l}\text { Saya merasa sulit untuk menerima kritik apapun, bereaksi dengan kemarahan, } \\
\text { kecemasan atau bahkan depresi jika kritik itu benar-benar datang }\end{array}$ & 12345 \\
\hline $\begin{array}{l}\text { Adakalanya saya sadar diri dan berpikir, saya akan memperlihatkan kepada mereka, } \\
\text { mereka tidak dapat melakukannya tanpa saya, jika saya mengalami situasi konflik atau } \\
\text { proposal dan rencana saya ditolak }\end{array}$ & 12345 \\
\hline $\begin{array}{l}\text { Selain meraih apa yang orang anggap keberhasilan besar, saya tetap merasa diri saya } \\
\text { belum puas dan terdorong untuk meraih hal-hal yang lebih besar dalam usaha untuk } \\
\text { merasa diri saya terbaik }\end{array}$ & 12345 \\
\hline $\begin{array}{l}\text { Saya bersedia membelokkan peraturan dan menggunakan topeng dari perilaku yang } \\
\text { tepat demi mencapai maksud saya }\end{array}$ & 12345 \\
\hline $\begin{array}{l}\text { Dalam batin saya merasa iri atas keberhasilan dan pencapaian dari para rekan atau } \\
\text { organisasi di area atau di bidang keahlian saya }\end{array}$ & 12345 \\
\hline $\begin{array}{l}\text { Saya sering tidka menyadari atau tidak memperhatikan tekanan-tekanan keuangan yang } \\
\text { dibebankan karena tujuan-tujuan dan proyek-proyek saya pada mereka yang saya } \\
\text { pimpin, keluarga saya, atau organisasi yang saya layani }\end{array}$ & 12345 \\
\hline $\begin{array}{l}\text { Keberhasilan atau kegagalan dalam suatu proyek mempunyai pengaruh langsung pada } \\
\text { citra diri dan harga diri saya }\end{array}$ & 12345 \\
\hline $\begin{array}{l}\text { Saya sangat menyadari bagaimana rekan-rekan dan mereka yang menerima tanggung } \\
\text { jawab saya mempertimbangkan pencapaian saya }\end{array}$ & 12345 \\
\hline $\begin{array}{l}\text { Saya butuh dikenal atau di puncak ketika bertemu dengan suatu kelompok rekan } \\
\text { pemimpin atau para sejawat }\end{array}$ & 12345 \\
\hline $\begin{array}{l}\text { Saya memandang diri saya sebagai tokoh yang dikenal secara rasional di masa } \\
\text { mendatang atau berencana untuk meraih posisi seperti ini }\end{array}$ & 12345 \\
\hline
\end{tabular}

Jumlahkan bilangan yang dilingkari dan tempatkan jumlahnya di sini:

Jika jumlah kurang dari 20, mungkin anda bukan narsisistik. Jika jumlah anda di antara 21 dan 40 ada kemungkinan anda memiliki beberapa kecenderungan narsisistik. Jika jumlah anda adalah 41 atau lebih, anda mungkin adalah seorang pemimpin yang narsisistik.

Test Untuk mengetahui Apakah anda pemimpin Paranoid?[18]

1-Sangat tidak setuju; 2-Tidak setuju; 3-Ragu-ragu; 4-Setuju; 5-Sangat setuju

Tabel 3. Test Pemimpin Paranoid 


\begin{tabular}{|c|c|}
\hline $\begin{array}{l}\text { Ketika saya melihat } 2 \text { pemimpin kunci dari organisasi, saya berbicara pelan-pelan, saya } \\
\text { khawatir mereka mungkin membicarakan saya }\end{array}$ & 12345 \\
\hline $\begin{array}{l}\text { Saya sangat terganggu bila memikirkan pemimpin saya atau pertemuan tim } \\
\text { kepemimpinan tanpa kehadiran saya }\end{array}$ & 12345 \\
\hline $\begin{array}{l}\text { Ketika rekan menerima sambutan hangat atas suatu kelompok proyek atau penugasan } \\
\text { khusus, saya mengalami rasa iri yang berat daripada sukacita di dalam keberhasilan dan } \\
\text { penghargaan yang dia terima }\end{array}$ & 12345 \\
\hline $\begin{array}{l}\text { Saya mengharuskan para bawahan dan rekan-rekan di dalam organisasi saya } \\
\text { memberikan laporan mendetail tentang aktivitas mereka }\end{array}$ & 12345 \\
\hline $\begin{array}{l}\text { Saya bergumul ketika seorang rekan, bukannya saya, diminta untuk menangani suatu } \\
\text { penugasan khusus atau proyek yang canggih }\end{array}$ & 12345 \\
\hline $\begin{array}{l}\text { Saya memiliki sedikit hubungan yang akrab dan bermakna di dalam organisasi, saya } \\
\text { mendapati diri saya menghindari hubungan-hubungan yang demikian }\end{array}$ & 12345 \\
\hline $\begin{array}{l}\text { Saya menekankan kesetiaan mutlak dari mereka yang bekerja untuk saya dan melarang } \\
\text { staf mengkritik saya dalam hal apapun }\end{array}$ & 12345 \\
\hline $\begin{array}{l}\text { Saya sering khawatir bahwa ada satu kelompok yang signifikan di dalam organisasi } \\
\text { saya yang menginginkan saya pergi }\end{array}$ & 12345 \\
\hline $\begin{array}{l}\text { Saya telah menanyai orang-orang tentang apa yang mereka ketahui atau tentang } \\
\text { informasi khusus yang mereka miliki berkenaan dengan para pemimpin di dalam } \\
\text { organisasi saya }\end{array}$ & 12345 \\
\hline $\begin{array}{l}\text { Mereka yang mempekerjakan saya sering mengeluh tentang kekurangan saya terhadap } \\
\text { cara humor }\end{array}$ & 12345 \\
\hline $\begin{array}{l}\text { Secara rutin saya menunjuk mereka yang saya pimpin sebagai "orang-orang saya" atau } \\
\text { "organisasi saya", namun geram ketika sebutan yang sama diucapkan oleh seorang } \\
\text { rekan }\end{array}$ & 12345 \\
\hline $\begin{array}{l}\text { Saya bahkan cenderung menganggap serius terhadap komentar atau lelucon ringan yang } \\
\text { ditujukan pada saya, merasa mungkin ada kebenaran di dalamnya }\end{array}$ & 12345 \\
\hline
\end{tabular}

Jumlahkan bilangan yang dilingkari dan tempatkan jumlahnya di sini:

Jika jumlah kurang dari 20, mungkin anda bukan paranoid. Jika jumlah anda di antara 21 dan 40 ada kemungkinan anda memiliki beberapa kecenderungan paranoid. Jika jumlah anda adalah 41 atau lebih, anda mungkin adalah seorang pemimpin yang paranoid.

Test untuk mengetahui apakah anda pemimpin kondenpenden?[19]

1: Sangat tidak setuju; 2: tidak setuju; 3: ragu-ragu; 4: setuju; 5: sangat setuju

Tabel 4. Test pemimpin kondependen

\begin{tabular}{|c|c|}
\hline $\begin{array}{l}\text { Saya tumbuh di dalam keluarga dengan satu atau lebih orang-orang } \\
\text { yang dependen pada substansi (alkoholik, pecandu obat-obatan, } \\
\text { pencandu makanan, dan lain-lain) }\end{array}$ & 12345 \\
\hline $\begin{array}{l}\text { Saya bertumbuh di dalam lingkungan yang kaku, legalistic, yang } \\
\text { memperlakukan standard perilaku yang tidak realistic kepada anggota } \\
\text { keluarga dan melarang diskusi yang terbuka, jujur, mengenai } \\
\text { masalah-masalah dan pergumulan pribadi }\end{array}$ & 12345 \\
\hline $\begin{array}{l}\text { Saya biasanya toleran atau mengabaikan perilaku orang-orang lain } \\
\text { yang aneh, memalukan dan yang tidak patut }\end{array}$ & 12345 \\
\hline $\begin{array}{l}\text { Saya sering menghindari dari membagikan pendapat saya di dalam } \\
\text { tatanan kelompok kecil sampai saya sudah mendengar pendapat dari } \\
\text { orang lain di dalam kelompok itu }\end{array}$ & 12345 \\
\hline $\begin{array}{l}\text { Saya sering kali khawatir melukai perasaan orang lain jika } \\
\text { membagikan perasaan dan pemikiran saya yang sebenarnya }\end{array}$ & 12345 \\
\hline $\begin{array}{l}\text { Saya sering merasa bertanggung jawab atas masalah-masalah yang } \\
\text { tidak saya buat }\end{array}$ & 12345 \\
\hline $\begin{array}{l}\text { Saya sulit tidur karena mengkhawatirkan masalah atau perilaku } \\
\text { seseorang }\end{array}$ & 12345 \\
\hline $\begin{array}{l}\text { Saya dapati diri saya seringkali terlalu mengabdi dan merasa hidup } \\
\text { saya sudah tidak terkendali }\end{array}$ & 12345 \\
\hline $\begin{array}{l}\text { Saya merasa amat sangat sulit mengatakan "tidak" kepada orang lain } \\
\text { walaupun saya tahu bahwa mengatakan ya akan mengakibatkan } \\
\text { kesulitan bagi saya dan keluarga }\end{array}$ & 12345 \\
\hline $\begin{array}{l}\text { Saya secara konstan merasakan suatu citra bersalah namun kesulitan } \\
\text { mencari sumbernya }\end{array}$ & 12345 \\
\hline $\begin{array}{l}\text { Saya merasa seperti tidak pernah cocok dengan mereka yang ada di } \\
\text { sekitar saya dan memiliki pikiran mencela diri }\end{array}$ & 12345 \\
\hline $\begin{array}{l}\text { Ketika saya menerima penghormatan dari orang lain, saya merasa } \\
\text { sulit hanya sekedar menerimanya tanpa membuat pernyataan yang }\end{array}$ & 12345 \\
\hline
\end{tabular}


Jumlahkan bilangan yang dilingkari dan tempatkan jumlahnya di sini:

Jika jumlah anda kurang dari 20, mungkin anda bukan kondependen. Jika jumlah anda di antara 21 dan 40, ada kemungkinan anda memiliki beberapa kecenderungan kodependen. Jika jumlah anda adalah 41 atau lebih, anda mungkin adalah seorang pemimpin yang kodependen

Test untuk mengetahui apakah anda pemimpin pasif agresif?[20]

1: Sangat tidak setuju; 2: tidak setuju; 3: ragu-ragu; 4: setuju; 5: sangat setuju

Tabel 5. Test Pemimpin pasif-agresif

\begin{tabular}{|c|c|}
\hline $\begin{array}{l}\text { Saya dapati diri saya menolak standard an prosedur untuk } \\
\text { peninjauan formal atas penampilan saya }\end{array}$ & 12345 \\
\hline $\begin{array}{l}\text { Sudah biasa bagi saya untuk menangguhkan proyek-proyek } \\
\text { utama yang harus saya lakukan }\end{array}$ & 12345 \\
\hline $\begin{array}{l}\text { Saya selalu menolak ide-ide orang lain yang bisa menyebabkan } \\
\text { bertambahnya pekerjaan atau tanggung jawab bagi saya }\end{array}$ & 12345 \\
\hline $\begin{array}{l}\text { Saya dapati diri saya selalu berkinerja di bawah kemampuan } \\
\text { saya }\end{array}$ & 12345 \\
\hline $\begin{array}{l}\text { Saya mengalami ledakan-ledakan periodic namun berulang } \\
\text { ulang dari kemarahan dan frustasi yang hanya berada di dalam } \\
\text { batas-batas dari apa yang dianggap perilaku yang dapat diterima }\end{array}$ & 12345 \\
\hline $\begin{array}{l}\text { Kadang kala secara sengaja saya melupakan proyek yang } \\
\text { diusulkan }\end{array}$ & 12345 \\
\hline $\begin{array}{l}\text { Kadang kala saya berdiam diri sebagai ungkapan kemarahan } \\
\text { saya kepada orang lain }\end{array}$ & 12345 \\
\hline $\begin{array}{l}\text { Saya dapati diri saya mengatakan kepada orang lain bahwa tidak } \\
\text { ada yang menganggu saya, ketika kenyataannya bahwa saya } \\
\text { sedang geram }\end{array}$ & 12345 \\
\hline $\begin{array}{l}\text { Saya cenderung menjadi pesimistik secara umum dan merasa } \\
\text { negative tentang masa depan saya }\end{array}$ & 12345 \\
\hline $\begin{array}{l}\text { Orang lain telah mengungkapkan kepada saya bahwa saya } \\
\text { membuat mereka merasa tidak nyaman }\end{array}$ & 12345 \\
\hline $\begin{array}{l}\text { Perencanaan strategi dan penentuan sasaran itu sulit bagi saya } \\
\text { dan saya menolak penerapan seperti ini }\end{array}$ & 12345 \\
\hline $\begin{array}{l}\text { Kadangkala saya sadar saya mencoba menipu orang lain di } \\
\text { dalam banyak setting kelompok dengan melepaskan kemarahan } \\
\text { dan emosi saya ketika menghadapi inisiatif yang tidak saya } \\
\text { dukung }\end{array}$ & 12345 \\
\hline
\end{tabular}

Jumlahkan bilangan yang dilingkari dan tempatkan jumlahnya di sini:

Jika jumlah anda kurang dari 20, mungkin anda bukan pasif-agresif. Jika jumlah anda di antara 21 dan 40, ada kemungkinan anda memiliki beberapa kecenderungan pasif-agresif. Jika jumlah anda adalah 41 atau lebih, anda mungkin adalah seorang pemimpin yang pasif-agresif

Hasil dari pengabdian, pelatihan dan penelitian dapat digambarkan dengan framework sebagai berikut: 


\section{The Trilogy of social media}

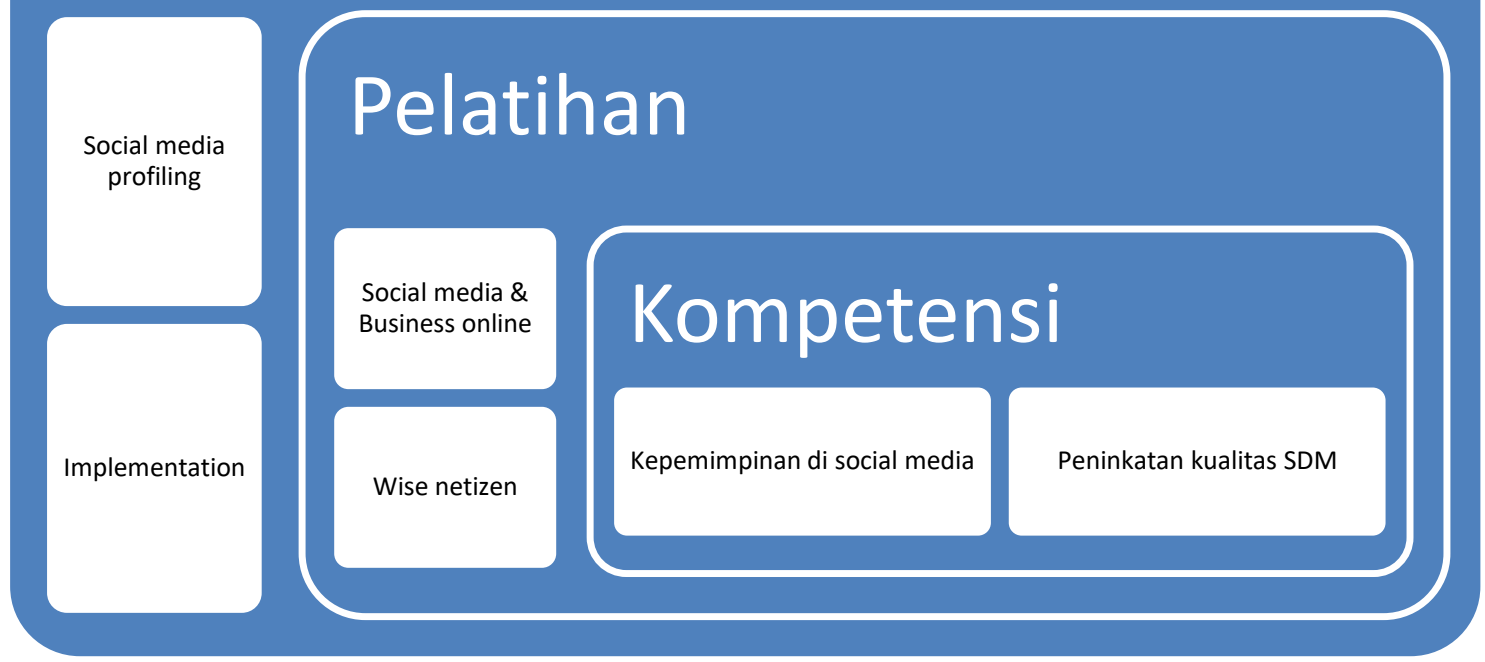

Gambar 7. Framework Social media profiling \& kompetensi

Gambar 7, menjelaskan bahwa setelah menyelesaikan pelatihan, maka dihasilkan peningkatan kualitas sumber daya manusia khususnya siswa dan guru dari sisi pengetahuan, konsep, inovasi dan kualitas lainnya. Pengabdian masyarakat ini masih belum selesai dan akan dilakukan pengabdian masyarakat, pelatihan lagi dengan pelatihan yang lebih mendalam mengenai social media.

\section{KESIMPULAN DAN SARAN}

Kesimpulan yang dapat diambil dari hasil pengabdian, pelatihan dan penelitian ini adalah:

1. Social media dapat digunakan sebagai sarana dalam meningkatkan jaringan atau koneksi dalam menawarkan produk/jasa kita, dan untuk berhasil mencapai hal tersebut, kita dapat menggunakan strategi internal dan eksternal

2. Menjadi seorang wise netizen artinya memiliki pengetahuan, data, mampu memberikan sebuah contoh studi kasus, solusi dan memiliki sopan santun dalam bertutur kata

3. Kepemimpinan di social media artinya memberikan pengaruh dan dampak positif kepada orang lain dan juga kemampuan untuk meningkatkan hal-hal yang positif, yang terdapat di dalam diri kita sendiri

\section{UCAPAN TERIMA KASIH}

Kami berterima kasih kepada seluruh SMA Negeri 3, atas kesempatan yang telah diberikan dalam membagikan ilmu pengetahuan dan pelatihan yang diberikan untuk dapat meningkatkan kualitas sumber daya manusia. Kami juga ingin berterima kasih kepada pihakpihak yang telah membantu kami dalam memberikan masukan dan informasi yang bermanfaat dalam menyelesaikan penelitian dan pengabdian masyarakat ini. 


\section{DAFTAR PUSTAKA}

[1] I. Gamayanto and F. Esti Nilawati, "Pengembangan dan Implementasi dari Wise Netizen (E-Comment) di Indonesia The Development And Implementation Of Wise Netizen (EComment) In Indonesia," Techno. COM, vol. 16, no. 1, pp. 80-95, 2017.

[2] I. Gamayanto, H. Christian, S. Wibowo, D. R. I. M. Setiadi, D. Purnamasari, and T. S. Sukamto, "Developing 'Leadership Intelligence (CI2) Framework' Inside Social Media to Develop An Ethical Leader using the Johari Window Method," Indones. J. Inf. Syst., vol. 1, no. 2, p. 119, 2019, doi: 10.24002/ijis.v1i2.1948.

[3] I. Gamayanto, H. Christian, S. Wibowo, and T. S. Sukamto, "Developing 'Culture Intelligence (CI3) Framework' Inside Social Media Using Johari Window Methods," Indones. J. Inf. Syst., vol. 1, no. 1, 2018.

[4] Ø. Kvalnes, Digital dilemmas: Exploring social media ethics in organizations. 2020.

[5] J. Viktil, "The Role of Social Media in the Communication of Leaders," 2011.

[6] D. C. Christopoulos, "The impact of social networks on leadership behaviour," Methodol. Innov., vol. 9, p. 205979911663064,2016 , doi: 10.1177/2059799116630649.

[7] A. M. Rorholm, "Power and Influence of the Modern Internet Opinion Leader," Open J. Hum. Resour. Manag., vol. 1, no. 1, p. 22, 2018, [Online]. Available: https://www.sryahwapublications.com/open-journal-of-human-resourcemanagement/pdf/v1-i1/3.pdf.

[8] sasono wibowo indra gamayanto, "Developing a techno - family through virtual - reality benthix game," J. Teknol. Pendidik., vol. 19, no. 2, pp. 113-138, 2020.

[9] F. Bria, "Social media and their impact on organisations: building firm celebrity and organisational legitimacy through social media," 2013.

[10] R. H. Nunes, J. B. Ferreira, A. S. de Freitas, and F. L. Ramos, "The effects of social media opinion leaders' recommendations on followers' intention to buy," Rev. Bras. Gest. Negocios, vol. 20, no. 1, pp. 57-73, 2018, doi: 10.7819/rbgn.v20i1.3678.

[11] S. Winter and G. Neubaum, "Examining Characteristics of Opinion Leaders in Social Media: A Motivational Approach," Soc. Media Soc., vol. 2, no. 3, 2016, doi: 10.1177/2056305116665858.

[12] D. Westman, P. Lindfors, and K. Hamde, "Leaders and Social Media Improving HRM through better internal communication," 2012.

[13] P.- Gilani, E. Bolat, and C. Wilkin, "Leadership Chaos : When Power is in the Hands of Followers," 2019.

[14] L. Cheng Ean (Catherine), "Social media and leadership communication: The use of social media by corporate leaders for effective internal communication," in China New Media Communication Association Annual Conference Macao International Conference, 2012, no. 1.

[15] S. D. R. Garly L Mcintosh, Overcoming The Darkside Of Leadership: How to become an effective leader by comfronting potential failures. 2007.

[16] F. Uguz, "Obsessive-compulsive disorder," Psychiatr. Disord. Dur. Postpartum Period Light Curr. Adv., vol. 19, no. 3, 2016, doi: 10.4102/sajpsychiatry.v19i3.951.

[17] A. Kumar Patel and S. Kumar Tiwari, "The Effect of Narcissism on Mental Well-Being in Middle Aged People," Indian J. Soc. Sci. Res., no. October 2015, 2015, [Online]. Available: https://www.researchgate.net/publication/322096564.

[18] K. C. Lewis and J. Ridenour, "Encyclopedia of Personality and Individual Differences," Encycl. Personal. Individ. Differ., no. January, 2017, doi: 10.1007/978-3-319-28099-8.

[19] G. Cowan, M. Bommersbach, and S. R. Curtis, "Codependency, loss of self, and power," Psychol. Women Q., vol. 19, no. 2, pp. 221-236, 1995, doi: 10.1111/j.14716402.1995.tb00289.x.

[20] C. J. Hopwood and A. G. C. Wright, "A comparison of passive-aggressive and negativistic personality disorders," J. Pers. Assess., vol. 94, no. 3, pp. 296-303, 2012, doi: 10.1080/00223891.2012.655819. 